\title{
Cigarette smoking and rate of gastric emptying: effect on alcohol absorption //
}

Richard D Johnson, Michael Horowitz, Anne F Maddox, Judith ML Wishart, David J C Shearman

Department of Medicine, Royal Adelaide Hospital, North Terrace, Adelaide, ) South Australia

Richard D Johnson, FRACP, senior visiting specialist Michael Horowitz, FRACP, associate professor of medicine Judith $M$ Wishart, BSC, research assistant David J C Shearman, FRACP, professor of medicine

Department of Nuclear Medicine, Royal Adelaide Hospital, North Terrace, Adelaide, South Australia Anne F Maddox, MIR, research assistant

Correspondence and requests for reprints to: Dr Johnson.

$B M \mathcal{1} 1991 ; 302: 20-3$

\section{Abstract}

Objective-To examine the effects of cigarette smoking on alcohol absorption and gastric emptying. Design-Randomised crossover study.

Setting-Research project in departments of medicine and nuclear medicine.

Subjects-Eight healthy volunteers aged 19-43 who regularly smoked $20-35$ cigarettes a day and drank small amounts of alcohol on social occasions.

Interventions -Subjects drank $400 \mathrm{ml}$ of a radiolabelled nutrient test meal containing alcohol $(0.5 \mathrm{~g} / \mathrm{kg})$, then had their rates of gastric emptying measured. Test were carried out $(a)$ with the subjects smoking four cigarettes an hour and $(b)$ with the subjects not smoking, having abstained for seven days or more. The order of the tests was randomised and the tests were conducted two weeks apart.

Main outcome measures-Peak blood alcohol concentrations, absorption of alcohol at 30 minutes, amount of test meal emptied from the stomach at 30 minutes, and times taken for $50 \%$ of the meal to leave the proximal stomach and total stomach.

Results-Smoking was associated with reductions in $(a)$ peak blood alcohol concentrations (median values in non-smoking versus smoking periods 13.5 (range 8.7-22.6) $\mathrm{mmol} / \mathrm{l} v 11 \cdot 1(4 \cdot 3-13 \cdot 5) \mathrm{mmol} / \mathrm{l}$ ), (b) area under the blood alcohol concentrationtime curve at 30 minutes $\left(264 \times 10^{3}\left(0-509 \times 10^{3}\right)\right.$ $\left.\mathrm{mmol} / \mathrm{l} / \mathrm{min} v 140 \times 10^{3}\left(0-217 \times 10^{3}\right) \mathrm{mmol} / 1 / \mathrm{min}\right)$, and (c) amount of test meal emptied from the stomach at 30 minutes (39\% (5-86\%) v 23\% (0-35\%)). In addition, smoking slowed both the $50 \%$ gastric emptying time (37 (9-83) minutes $v 56(40-280)$ minutes) and the intragastric distribution of the meal. There was a close correlation between the amount of test meal emptied from the stomach at 30 minutes and the area under the blood alcohol concentration-time curve at 30 minutes $(r=0.91 ; p<0.0001)$.

Conclusion-Cigarette smoking slows gastric emptying and as a consequence delays alcohol absorption.

\section{Introduction}

Although alcohol and tobacco are among the most widely used drugs in the world and are often used together, little is known of their pharmacokinetic interactions. Like most other drugs, alcohol is absorbed predominantly from the small intestine by virtue of its enormous surface area as compared with the stomach. Because the rate of alcohol absorption is dependent on gastric emptying ${ }^{12}$ factors which modify gastric emptying will also modulate the rate of alcohol absorption. ${ }^{24}$ For example, the rate of alcohol absorption is slower when a beverage containing alcohol is consumed with or after a meal rather than on an empty stomach, ${ }^{2}$ faster after administration of metoclopramide and various forms of gastric surgery, and slower after administration of propantheline. ${ }^{45}$ The effect of tobacco smoking and nicotine on gastric emptying is controversial, studies finding increased, ${ }^{6}$ decreased, ${ }^{7 \cdot 10}$ or unchanged ${ }^{61112}$ rates of gastric emptying. To our knowledge the effect of tobacco smoking on alcohol absorption has not been studied. This study examines the effects of cigarette smoking on alcohol absorption and gastric emptying.

\section{Subjects and methods}

The studies were performed in eight normal volunteers (seven men, one woman) aged $19-43$ years (median 25) who smoked cigarettes regularly (20-35 a day). The subjects' body weights ranged from 65 to $98 \mathrm{~kg}$ (median $85 \mathrm{~kg}$ ). None was receiving any medicines and none had evidence of gastrointestinal disease. All drank small quantities of alcohol on social occasions, but alcohol was avoided for 48 hours before each measurement of gastric emptying. Written, informed consent was obtained in all cases and the study was approved by the human ethics committee of the Royal Adelaide Hospital.

Protocol-Each volunteer had measurements of gastric emptying performed in a crossover study $(a)$ while smoking four cigarettes an hour, beginning 15 minutes before the study, and $(b)$ while not smoking, having abstained from cigarettes for at least seven days. The order of the tests was randomised and they were conducted two weeks apart. Each study began at roughly 1600 , the subject having fasted since eating a standardised breakfast between 0700 and $0800 .{ }^{13}$ All the cigarettes were filtered, and their median nicotine and tar yields were 0.9 (range $0 \cdot 6-1 \cdot 1) \mathrm{mg}$ and $10(6-12) \mathrm{mg}$ per cigarette respectively. The liquid test meal $(400 \mathrm{ml})$ consisted of orange juice diluted in water, $0.5 \mathrm{~g}$ absolute alcohol per kg body weight, and 28-37 MBq indium-113m labelled diethylenetriaminepenta-acetic acid. ${ }^{2}$ The energy content of the orange juice (total carbohydrate $21.2 \mathrm{~g}$, sugar $16.4 \mathrm{~g}$, protein $1.6 \mathrm{~g}$, fat $0.2 \mathrm{~g}$ ) was $402 \mathrm{~kJ}$, and for a $70 \mathrm{~kg}$ subject an additional $1026 \mathrm{~kJ}$ was contained in the alcohol. The energy content for the meal for a $70 \mathrm{~kg}$ subject was therefore approximately $3.55 \mathrm{~kJ} / \mathrm{ml}$. The temperature of the meal ranged from $19^{\circ}$ to $21^{\circ} \mathrm{C}$ and its $\mathrm{pH}$ ranged from 3.9 to 4.0 .

Measurement of gastric emptying-Details of the isotope test have been reported. ${ }^{13}$ Each study was performed with the subject seated in front of a scintillation camera. The test meal was consumed within two minutes and the point of completion of the meal taken as time zero. Data were corrected for movement of the subject, radionuclide decay, and $\gamma$ ray (tissue) attenuation. ${ }^{13}$ From the curves of gastric emptying (expressed as a percentage of the total meal remaining within the stomach over time) we derived (a) the duration of the lag phase before any of the meal emptied into the stomach, $(b)$ the amount of the meal that had emptied from the stomach at 10,30 , and 60 minutes, and $(c)$ the time to $50 \%$ emptying of the total stomach. The total stomach was divided into proximal and distal regions of interest by using a line drawn half way along and at 90 degrees to the long axis. The time taken for $50 \%$ of the meal to leave the proximal gastric region was measured.

Measurement of blood alcohol concentrations - In each study blood samples for measurement of alcohol concentrations were taken from a catheter situated in 
a forearm vein five minutes before and five, 10, 15, 20, $30,45,60,75,90,105,120,135,150,165,180$, and 210 minutes after the test meal had been taken. To avoid possible contamination the skin was previously cleaned with a non-alcoholic antibacterial solution. Samples of blood were stored at $4^{\circ} \mathrm{C}$ and assayed for alcohol within 72 hours by gas-liquid chromatography. ${ }^{14}$ The areas under the venous blood alcohol concentrationtime curves between zero and 30 minutes, zero and 60 minutes, and zero and 210 minutes were calculated. ${ }^{\prime}$

Statistical analysis-Data were analysed with the Wilcoxon matched pairs signed ranks test and Pearson's product moment correlation. 95\% Confidence intervals were calculated and $\mathrm{p}$ values $<0.05$ taken as significant in all analyses.

\section{Results}

Blood alcohol concentrations-The areas under the venous blood alcohol concentration-time curves between zero and 30 minutes and zero and 60 minutes and the peak blood alcohol concentrations were significantly less during the smoking period compared with values during the non-smoking period (fig 1, table I). Most of the subjects had detectable but low blood alcohol concentrations at 210 minutes, and there was a non-significant reduction in the area under the blood alcohol concentration-time curve between zero and 210 minutes in the smoking period compared with the non-smoking period $(p=0.062)$.

Gastric emptying - Gastric emptying was significantly slower during the smoking period than when not smoking (table II, fig 2). In all subjects the emptying curve was non-linear, and in the non-smoking periods it usually approximated a monoexponential pattern. In all studies performed during smoking there was a lag phase (minimum duration four minutes) before any of the meal emptied from the stomach (table II). The $50 \%$ emptying time from the proximal gastric region was significantly greater during smoking (fig 2). There were significant correlations between the $50 \%$ emptying times from the proximal stomach and total stomach

FIG 1-Mean blood alcohol concentrations after consumption of test meal during smoking and non-smoking periods. Bars are $S E M$

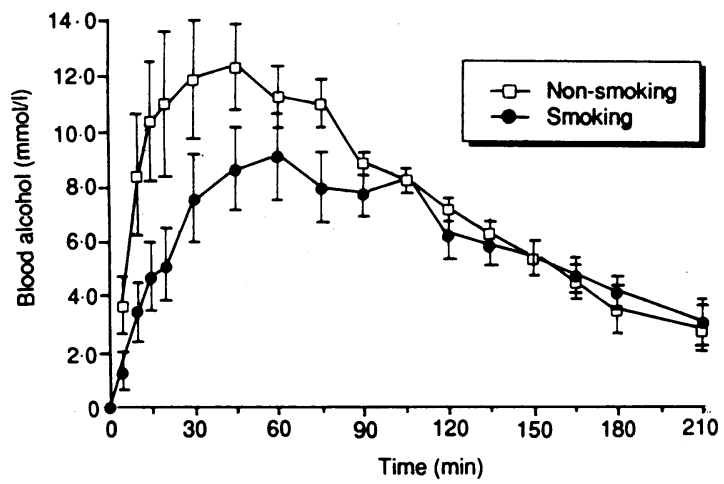

TABLE I-Median blood alcohol concentrations (ranges) during smoking and non-smoking periods

\begin{tabular}{lccc}
\hline Variable & Non-smoking & Smoking & p Value \\
\hline Peak blood alcohol $($ mmoll $)$ & $13 \cdot 5(8 \cdot 7-22 \cdot 6)$ & $11 \cdot 1(4 \cdot 3-13 \cdot 5)$ & $0 \cdot 008$ \\
Area under curve at 30 minutes $(\mathrm{mmol} / \mathrm{min})\left(\times 10^{3}\right)$ & $264(0-509)$ & $140(0-217)$ & $0 \cdot 014$ \\
Area under curve at 60 minutes $(\mathrm{mmo} / / \mathrm{min})\left(\times 10^{3}\right)$ & $647(80-909)$ & $469(62-562)$ & $0 \cdot 013$ \\
Area under curve at 210 minutes $(\mathrm{mmol} / \mathrm{min})\left(\times 10^{3}\right)$ & $1609(913-2132)$ & $1429(498-1827)$ & $0 \cdot 062$ \\
\hline
\end{tabular}

TABLE II-Median gastric emptying values (ranges) during smoking and non-smoking periods

\begin{tabular}{lrrc}
\hline Variable & Non-smoking & Smoking & p Value \\
\hline Lag (min) & $2(1-23)$ & $13(4-86)$ & $0 \cdot 010$ \\
Amount emptied at 10 minutes (\%) & $11(0-52)$ & $0(0-8)$ & $0 \cdot 010$ \\
Amount emptied at 30 minutes (\%) & $39(5-86)$ & $23(0-35)$ & $0 \cdot 014$ \\
Amount emptied at 60 minutes (\%) & $72(28-95)$ & $56(0-83)$ & $0 \cdot 013$ \\
$50 \%$ Emptying time from total stomach (min) & $37(9-83)$ & $56(40-280)$ & $0 \cdot 012$ \\
$50 \%$ Emptying time from proximal stomach (min) & $14(4-45)$ & $24(8-130)$ & $0 \cdot 014$ \\
\hline
\end{tabular}
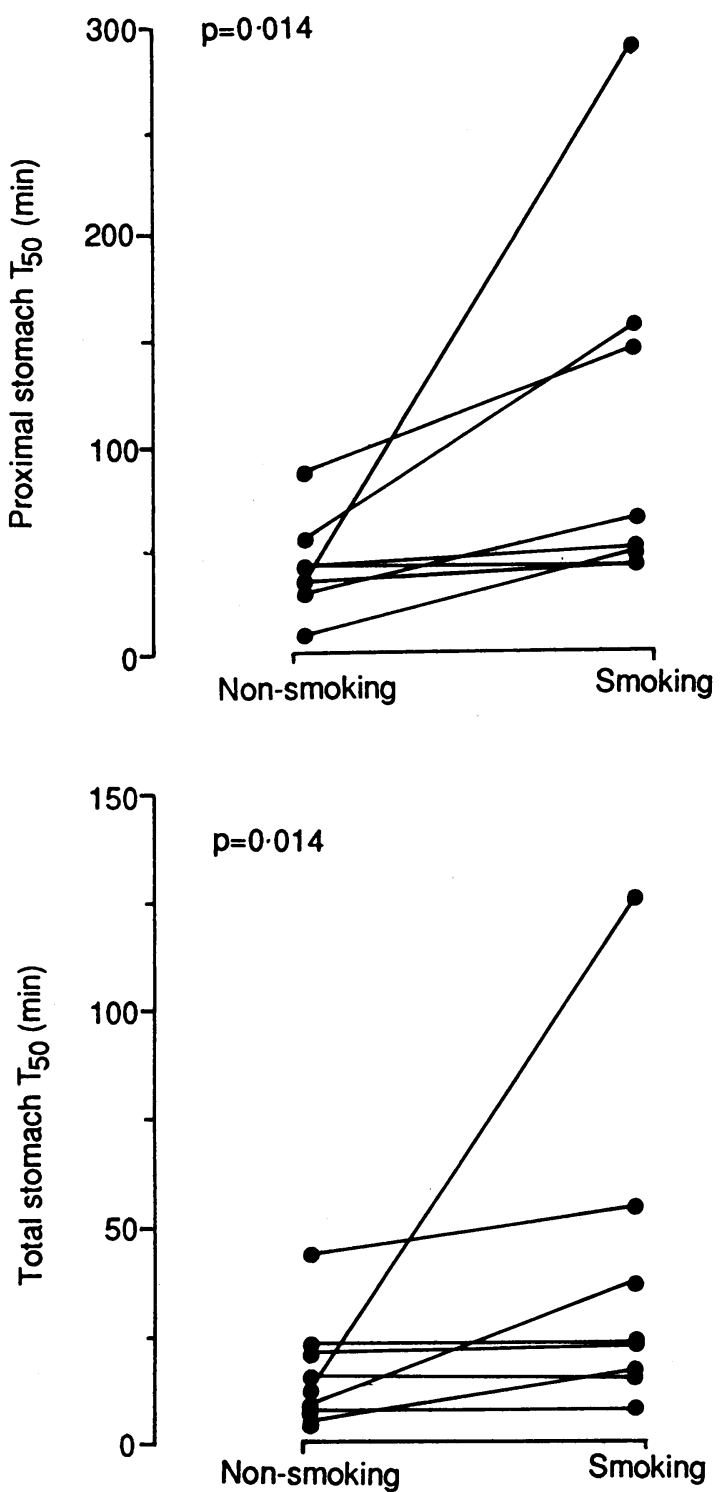

FIG 2-Individual 50\% emptying times $\left(T_{50}\right)$ from total stomach and proximal stomach during smoking and non-smoking periods

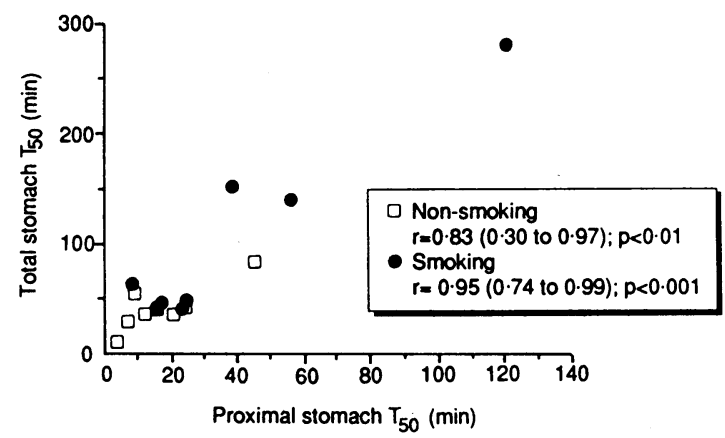

FIG 3-Relations between $50 \%$ emptying times $\left(T_{50}\right)$ from proximal stomach and total stomach during smoking and non-smoking periods. ( $r$ Values expressed with $95 \%$ confidence intervals in parentheses)

(fig 3) in both the non-smoking ( $\mathrm{r}=0.83$ (95\% confidence interval 0.30 to 0.97$) ; \mathrm{p}<0.01$ ) and smoking $(\mathrm{r}=0.95(0.74$ to 0.99$) ; \mathrm{p}<0.001)$ periods.

Relation between alcohol absorption and gastric emptying-The areas under the venous blood alcohol concentration-time curve between zero and 30 minutes and zero and 60 minutes correlated significantly with the amount of the meal emptied from the stomach at 30 minutes and 60 minutes respectively (fig 4 ). In the nonsmoking periods the correlations were $\mathrm{r}=0.95(95 \%$ confidence interval 0.74 to $0.99 ; \mathrm{p}<0.001$ ) and $\mathrm{r}=0.90$ $(0.53$ to $0.98 ; \mathrm{p}<0.001)$ respectively, whereas in the smoking periods the correlations were $\mathrm{r}=0.78(0 \cdot 17$ to 
FIG 4-Areas under venous blood alcohol concentration-time curve plotted against percentage of liquid meal emptied from stomach at 30 minutes and 60 minutes during smoking and non-smoking periods. ( $r$ Values non-smoking periods. ( $r$ Values
expressed with $95 \%$ confidence intervals in parentheses)

FIG 5-Relations between peak blood alcohol concentrations and $50 \%$ total gastric emptying time during smoking and non-smoking periods. ( $r$ Values expressed with $95 \%$ confidence interval in parentheses)
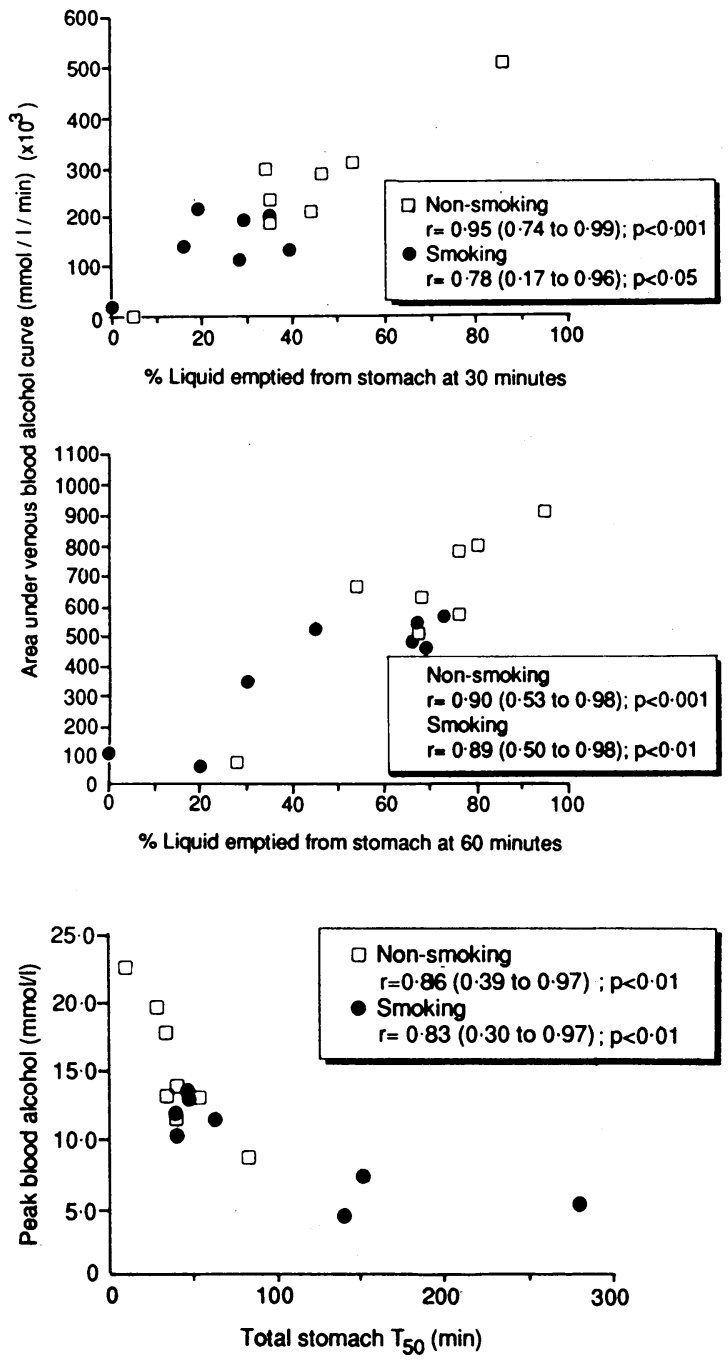

$0.96 ; \mathrm{p}<0.05)$ and $\mathrm{r}=0.89(0.50$ to $0.98 ; \mathrm{p}<0.01)$. In both the non-smoking and smoking periods there was a significant inverse relation between the peak blood alcohol concentrations and the $50 \%$ gastric emptying time (non-smoking period: $\mathrm{r}=0.86$ ( $95 \%$ confidence interval 0.39 to 0.97$), \mathrm{p}<0.01$; smoking period: $\mathrm{r}=0.83(0.30$ to 0.97$), \mathrm{p}<0.01)($ fig 5$)$.

\section{Discussion}

After ingestion of an equivalent, weight adjusted dose of alcohol there is considerable interindividual and intraindividual variation in the rate of absorption and peak blood alcohol concentrations. ${ }^{1}$ Our findings confirm that these differences are largely attributable to variations in the rate of gastric emptying. ${ }^{12}$ We studied only eight subjects. Nevertheless, a crossover design was used, which in seven of the eight subjects showed that the rate of total gastric emptying was slower during smoking. In the remaining subject the rate was unchanged (fig 2 ). Thus in this series cigarette smoking significantly reduced peak blood alcohol concentrations and delayed alcohol absorption, presumably by slowing gastric emptying.

These observations have considerable social and medicolegal relevance. It is legally permissible to back calculate to the time of a motor vehicle accident the blood alcohol concentration in motorists suspected of drink-driving offences. The variability in peak blood alcohol concentrations in this study points to the limitations of back calculation of blood alcohol concentrations. ${ }^{15}$ Moreover, smoking and nicotine intake should be controlled for in studies of alcohol absorption, unlike in previous studies. ${ }^{16-19}$

The effect of smoking and nicotine on gastric emptying has been the subject of several studies. ${ }^{6-12}$ In all but one study ${ }^{6}$ smoking was found to delay gastric emptying of a digestible solid meal. ${ }^{70}$ Miller et al and Petring $e t$ al found that smoking did not affect the rate of emptying of a liquid meal. ${ }^{11}$ Petring et al used the rate of paracetamol absorption as an indirect measure of liquid gastric emptying, and this technique is known to be fairly insensitive. ${ }^{20}$ Miller et al studied gastric emptying of water, and their observations may be accounted for by the absence of nutrients in the liquid meal. We have shown that smoking significantly slows gastric emptying of a liquid meal containing nutrients and that this delay reflects, at least in part, slowing of the intragastric distribution of the meal.

The contribution of nicotine to the delay in gastric emptying produced by cigarette smoking remains controversial. Gritz et al found that gastric emptying of a solid meal was slightly but significantly delayed after smoking high versus low nicotine cigarettes. ${ }^{9}$ They did not, however, include a "non-smoking" test. In other studies ingestion of nicotine gum had no effect on gastric emptying..$^{1012}$

There is little information about the motor mechanisms by which cigarette smoking slows gastric emptying. McDonnell and Owyang have recently shown that smoking inhibits antral contractions, ${ }^{21}$ which may account for slowed gastric emptying of digestible solid meals. Nicotine reportedly inhibits antral contractions in dogs. ${ }^{22}$ Valenzuela et al reported that smoking decreased basal pyloric pressure, ${ }^{23}$ but in the light of current knowledge ${ }^{24}$ the methodology used in their study must be considered to be technically inadequate and the results viewed with scepticism. The slowing of the intragastric distribution suggests that cigarette smoking decreases proximal gastric tone, which may account for the slowed emptying of a nutrient liquid meal. ${ }^{25}$ In view of the probable crucial role of the pylorus in the regulation of nutrient liquid emptying, however, ${ }^{26} 27$ the effect of smoking on pyloric motility warrants further study with improved methodology. Muller-Lissner reported that duodenogastric reflux is increased by smoking. ${ }^{8}$ The retardation of gastric motility produced by smoking may be important in the pathogenesis of gastroesophageal reflux ${ }^{28}$ and the reported effects of cigarette smoking on satiety..$^{29}$

The area under the blood alcohol concentration-time curve at 30 minutes was taken as the index of the rate of alcohol absorption in this and other studies ${ }^{12}$ on the basis that the rate of absorption at 30 minutes was much greater than the rate of hepatic metabolism. We now know, however, that the stomach metabolises alcohol by virtue of the presence of alcohol dehydrogenase in gastric mucosa, ${ }^{6-19}$ and at low doses of alcohol $(0.15 \mathrm{~g} / \mathrm{kg})$ consumed in the fed state this "first pass" effect is significant. The magnitude of this effect is likely to be greater if there is more prolonged contact of alcohol with the gastric mucosa because of slowed gastric emptying. Therefore, although much higher doses of alcohol $(0.5 \mathrm{~g} / \mathrm{kg})$ were used in our study and the subjects were fasting, possibly gastric metabolism of alcohol contributed to the significant reduction in the area under the blood alcohol concentration-time curve at 30 and 60 minutes and the trend for a significant reduction at 210 minutes in the smoking period as well as slower gastric emptying. We could not assess total alcohol absorption because the blood alcohol concentrations did not reach zero in all subjects.

The computer program used to divide the stomach into proximal and distal regions was developed by $\mathrm{Mr}$ P Collins. The study was funded by the Australian Associated Brewers.

1 Holt S. Observations on the relation between alcohol absorption and the rate of gastric emptying. Can Med Assoc f 1981;124:267-77. 
2 Horowitz M, Maddox A, Bochner M, et al. Relationships between gastric emptying of solid and caloric liquid meals and alcohol absorption. Am F Physiol 1989;257:G291-8.

3 McFarlane A, Pooley L, Welch I McL, Rumsey RDE, Read NW. How doe dietary lipid lower blood alcohol concentrations? Gut 1986;27:15-8.

4 Finch JE, Kendall MJ, Mitchard $M$. An assessment of gastric emptying by breathalyser. Br f Clin Pharmacol 1974;1:223-6.

5 Cotton PB, Walker G. Ethanol absorption after gastric operations and in the coeliac syndrome. Postgrad Med f 1973;49:27-8.

6 Grimes DS, Goddard J. Effect of cigarette smoking on gastric emptying. BMf 1978;ii:460-1

7 Nowak A, Jonderko K, Kaczor R, Nowak S, Skrzypek D. Cigarette smoking delays gastric emptying of a radiolabelled solid food in healthy smokers. Scand 7 Gastroenterol 1987:22:54-8.

8 Muller-Lissner SA. Bile reflux is increased in cigarette smokers. Gastroenterolog 1986;90:1205-9.

9 Gritz ER, Ippoliti A, Jarvik ME, et al. The effect of nicotine on the delay of gastric emptying. Alimentation, Pharmacology and Therapy 1988;2:173-8.

10 Miller G, Palmer KR, Smith B, Ferrington C, Merrick MV. Smoking delays gastric emptying of solids. Gut 1989;30:50-3.

1 Petring OU, Adelhoj B, Ibsen M, Brynnum J, Poulsen HE. Abstaining from cigarette smoking has no major effect on gastric emptying in habitual smokers. Br f Anaesth 1985;57:1104-6.

12 Chaudhuri TK, Fink S. Effect of nicotine gum on gastric emptying. Chest 1988;94:1122.

13 Collins PJ, Horowitz M, Cook DJ, Harding PE, Shearman DJC. Gastric emptying in normal subjects: a reproducible technique using a singl scintillation camera and computer system. Gut 1983;24:117-25.

14 Cooper JDH. Determination of blood ethanol by gas chromatography. Clin Chim Acta 1971;33:483-5.

15 Lewis KO. Back calculation of blood alcohol concentration. BMf 1987;295 800-1.

16 DiPadova C, Worner TM, Julkunen RJK, Leiber CS. Effects of fasting and chronic alcohol consumption on the first-pass metabolism of ethanol. Gastroenterology 1987;92:1169-73.

17 Caballeria J, Baraona E, Rodamilans M, Leiber CS. Effects of cimetidine on gastric alcohol dehydrogenase activity and blood ethanol levels. Gastroenterology 1989;96:388-92.

18 Caballeria J, Frezza M, Hernandez-Munoz R, et al. Gastric origin of the first-pass metabolism of ethanol in humans: effect of gastrectomy. Gastroenterology 1989;97:1205-9.

19 Frezza M, DiPadova C, Pozzato G, Terpin M, Baraona E, Lieber CS. High blood alcohol levels in women; the role of decreased gastric alcohol dehydrogenase activity and first-pass metabolism. $N$ Engl f Med 1990;322: 95-9.

20 Horowitz M, Collins PJ, Shearman DJC. Disorders of gastric emptying and the application of radionuclide methods. Arch Intern Med 1985;145:1467-75. 21 McDonnell WM, Owyang C. Smoking markedly inhibits gastric motility in smokers and nonsmokers [Abstract]. Gastroenterology 1989;96:A332.

22 Carlson GM, Rudden RW, Hug CC, Schmiege SK, Bass P. Analysis of the site of nicotine action on gastric antral and duodenal contractile activity. I Pharmacol Exp Ther 1970;172:377-83.

23 Valenzuela JE, Defilippi C, Csendes A. Manometric studies on the human pyloric sphincter: effect of cigarette smoking, metoclopramide, and atropine pyloric sphincter: effect of cigare
Gastroenterology 1976;70:481-3.

24 Heddle R, Dent J, Toouli J, Read NW. Topography and measurement of pyloric pressure waves and tone in humans. Am f Physiol 1989;255:G491-7. 25 Azpiroz F, Malagelada JR. Intestinal control of gastric tone. Am f Physiol 1985;249:G501-9.

26 Heddle R, Fone D, Dent J, Horowitz M. Stimulation of pyloric motility by intraduodenal dextrose in normal subjects. Gut 1988;29:1349-57.

27 Houghton LA, Read NW, Heddle R, et al. Relationship of the motor activity of the antrum, pylorus and duodenum to gastric emptying of a solid-liquid mixed meal. Gastroenterology 1988;94:1285-91.

28 McCallum RW, Mensch R, Lange R. Definition of the gastric emptying abnormality present in gastroesophageal reflux patients [Abstract]. Gastroenterolgy 1981;80:A1226.

29 Grunberg NE. Nicotine as a psychoactive drug: appetite regulation. Psychopharmacol Bull 1986;22:875-81.

(Accepted 18 September 1990)
Infectious Diseases Unit, Department of Medicine, Royal Postgraduate Medical School, London W12 0HS

Rachanee CheingsongPopov, PHD, senior research officer

Christina Panagiotidi, MSC, technician

Jonathan Weber, MRCP, senior lecturer

Department of Haematology, Royal Postgraduate Medical School, London W12 0HS Stella Bowcock, MRCP, senior registrar

\section{Treloar Haemophilia} Centre, Lord Mayor

Treloar College, Hampshire

Anthony Aronstam, FRCPATH, consultant

haematologist

Academic Department of Public Health, St Mary's Hospital Medical School, London W2 1PG

Jane Wadsworth, PHD, senior lecturer

Correspondence to:

Dr J Weber,

Jefferiss Wing, St Mary's

Hospital Medical School

London W2 1NY.

BMF 1991;302:23-6

\title{
Relation between humoral responses to HIV gag and env proteins at seroconversion and clinical outcome of HIV infection
}

\author{
Rachanee Cheingsong-Popov, Christina Panagiotidi, Stella Bowcock, Anthony Aronstam,
} Jane Wadsworth, Jonathan Weber

\section{Abstract}

Objective-To study the contribution of the humoral response to HIV-I at seroconversion to disease outcome after 84 months.

Design-A retrospective longitudinal study.

Setting-Two haemophilia centres in the United Kingdom.

Patients - 88 Haemophiliac patients infected with HIV-I for whom sera were available from before seroconversion and in whom clinical follow up data were available.

Results-Kaplan-Meier survival analysis showed a significant difference between a high titre $(>1600)$ p24 antibody response at seroconversion and prolonged time before the development of HIV related disease $(p=0.0008)$. In contrast, higher titres of antibody to gp120 at seroconversion $(>25600)$ correlated with more rapid clinical deterioration $(\mathbf{p}=\mathbf{0 . 0 2 5})$.

Conclusions - The first humoral response to HIV proteins at seroconversion is associated with clinical outcome; patients with an initial low titre antibody response to the gagp 24 protein have a significantly faster rate of progression to CDC stage IV disease. Patients with a high titre p24 antibody response progress to AIDS more slowly, and these data provide an explanation why p24 antigenaemia is not universally detected in patients with AIDS. It is unclear whether the association between a strong initial p24 antibody response and slower progression of HIV disease is causal and if so whether it is due to viral or host factors.

\section{Introduction}

After infection with HIV-I there is a vigorous humoral response to structural and regulatory viral antigens. ${ }^{1-8}$ Antibodies to the env gene products gp160/gp120 and gp41 are produced early followed shortly by antibodies to the gag gene product $\mathrm{p} 24 . .^{910}$ By studying sequential serum samples from infected patients we and other investigators have found that there is an apparent lowering of titre of p24 (gag) antibodies in patients with more rapid progression to HIV related disease (AIDS related complex and AIDS $)^{11-17}$ whereas no such change is seen with gp41 (env) antibodies.

Subsequently, it has been repeatedly shown that $50-70 \%$ of patients with AIDS have detectable titres of serum p24 antigen whereas only rarely is p24 antigen detectable in asymptomatic patients ${ }^{18-21}$; detection of p24 antigen before symptomatic disease correlated significantly with prognosis over 27 months. ${ }^{19}$ The loss of antibody precedes p24 antigenaemia by 12-18 months, ${ }^{22}$ and this has been interpreted as being due to the formation of immune complexes of p24 antibodies with rising concentrations of p24 antigen. ${ }^{23}{ }^{24} \mathrm{We}$ have recently shown, however, that undetectable titres of p24 antibodies in antigenaemic patients do not rise after the reduction of p24 antigen titre with zidovudine treatment ${ }^{25}$; this suggests that the mechanism for the decline in titre of p24 antibody is unlikely to be the simple formation of immune complexes. Cohort data have shown that over time increasing numbers of patients with preserved high titres of p24 antibody and without detectable titres of p24 antigen develop AIDS, and the association of loss of p24 antibodies with prognosis becomes less significant (unpublished data). ${ }^{25}$ No explanation has yet been offered for these findings or for the failure to detect viral antigens in $30-50 \%$ of patients with AIDS, even when plasma viraemia can be readily detected. ${ }^{26}{ }^{27}$ As the presence of p24 antigen has been used as a surrogate marker of virus replication these data require elucidation

We thus studied the role of the first humoral response to HIV gag, env proteins at seroconversion 